\title{
Energy response of a mono-axis tracked solar thermal collector with vacuum tubes
}

\author{
V.E. Dombi ${ }^{1}$, I. Visa $^{1}$, D.V. Diaconescu ${ }^{1}$, M.M. Vatasescu ${ }^{1}$ and N.I.Tatu ${ }^{1}$ \\ ${ }^{1}$ Department Renewable Energy Systems and Recycling \\ Transilvania University of Braşov \\ B-ul Eroilor, 29, 500036 Braşov (Romania) \\ Phone/Fax number: +40-(268) 41.20.88,+40-(268) 41.05.25, e-mail: veronica.dombi@unitbv.ro
}

\begin{abstract}
Looking towards a sustainable future, Transilvania University of Brasov develops many projects on diverse renewable energy conversion systems; this paper presents a solar tracked solar thermal collector (STC) system, designed for a future implementation on Transilvania University campus. The specific requirement is that the STC system has to be configured to keep a zero energy response during the summer holydays (when the energy consumption is null). The proposed solution describes a mono-axial solar tracking system designed to perform an annual step wise tracking program to capture the most of the available solar energy using a solar thermal collector (STC) with vacuum tubes. The tracking program represents an optimised step tracking law developed in dependence with the diurnal movement of the sun.
\end{abstract}

Numerical simulations are done for one year interval, for Brasov Romania geographic site, to evaluate the daily variations of: the pseudo-equatorial solar angles $(\gamma, \beta)$; the pseudo-equatorial tracking angles $\left(\gamma^{*}, \beta^{*}\right)$; the incidence angle; the available beam solar radiation $(\mathrm{B})$ and the beam received solar radiation by the STC system (B*).

The energy response of the tracked STC, for Brasov, Romania, is evaluated considering both clear sky and cloudy sky conditions, while neglecting the diffuse radiation effect.

\section{Key words}

Pseudo-equatorial tracking programme, beam solar radiation, solar thermal collector (STC) with vacuum tubes, solar thermal collector's efficiency, tracking efficiency

\section{Introduction}

Sustainable development is the way towards a safe and a quality future life. Accordingly, the EU institutions (e.g. IEE, SEE, EC-Energy) have designated one top priority: supporting the research and implementation of renewable conversion energy systems.

Aligning our efforts to the world's direction towards a sustainable development, this paper presents a solar thermal collector (STC) (Fig. 1), easy to manage and maintain, designed to be implemented on Transilvania University campus, Brasov-Romania $\left(45,65^{\circ}\right.$ lat. N) [1].

Even though the bi-axial pseudo-equatorial tracking. programme leads to an over $99 \%$ tracking efficiency for PV systems [2], it can not be implemented on a STC system because of the pipe structure restrictions [3]. Therefore a STC can be tracked only according to a mono-axial tracking law, which can ensure an up to $95 \%$ tracking efficiency [2]

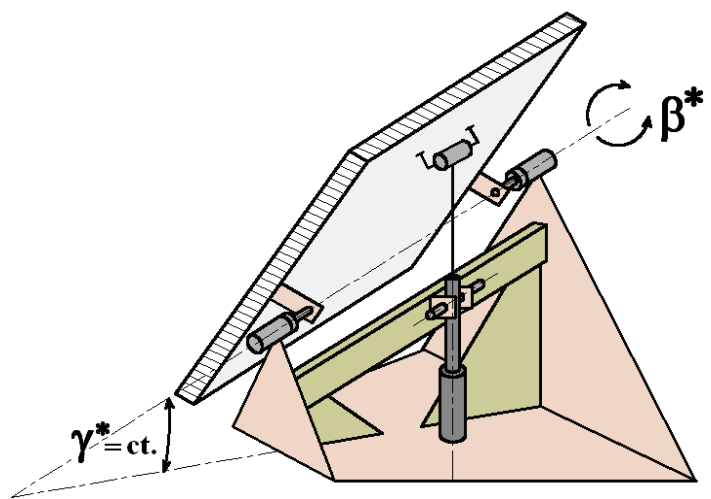

Fig. 1. The mono-axial, pseudo-equatorial STC, tracked according to an optimum annual constant elevation angle $\gamma^{*}=$ $38^{\circ}[3]$ and according to an annual $\beta^{*}$ hourly step tracking program (Fig. 9)

For the mono-axial pseudo-equatorial model the tracking law (programme) can be set either for the elevation movement $\left(\gamma^{*}\right)$ - used on string structures [5] - either on the diurnal movement $\left(\beta^{*}\right)$ - used on the stand alone systems.

Because the diurnal movement $\left(\beta^{*}\right)$ has a higher influence in increasing the energetic response than the elevation movement $\left(\gamma^{*}\right)$ [4], the proposed mono-axial pseudo-equatorial stand-alone STC (Fig. 1) functions according to an annual constant $\gamma^{*}=38^{\circ}$ [3] and on an hourly step-wise annual $\beta *$ tracking programme [3]. 


\section{Pre-requisites for the diurnal tracking programme modelling}

For the present study is considered the STC from Viessman [6]

When considering a tracked STC it is highly important to set the maximum angular stroke covered by the tracking programme (herein: the diurnal stroke $\Delta \beta *$ ) which must be performed without damaging the connecting pipes network [3]. Therefore, when considering the maximum angular stroke for a STC tracking programme there are two contradictory aspects that need to be simultaneously accomplished:

1) a large diurnal angular stroke is needed to cover almost the entire solar trajectory on the sky, so to harvest the maximum amount of beam solar radiation;

2) a minimum diurnal angular stroke is needed for the specific tracking movements, not to damage the STC pipe structure during

The compromise situation, in which the energy response is the least reduced by the two contradictory requirements, needs to be found, so to obtain the optimum diurnal stroke $\left(\Delta \beta^{*}\right)$ for the proposed mono-axial tracked STC (Fig. 1).

The proposed mono-axial STC is designed to be implemented on Transilavania University campus, therefore it should be turned-on during September to June interval and it should be turned-off during the summer holidays interval, when the thermal energy consumption is null. So another two specific requirements need to be accomplished, by modelling $\beta^{*}$ tracking programme:

- Excepting the summer holidays ( $1^{\text {st }}$ of July to $31^{\text {st }}$ of August), the system must reach an over $90 \%$ tracking efficiency by covering a minimum diurnal angular stroke $\left(\Delta \beta^{*}\right)$ and not damaging the STC pipes during the specific tracking movements.

- To identify the diurnal angular stroke $\left(\Delta \beta^{*}\right)$ which lead to a zero tracking efficiency $(\eta \mathrm{TRK}=0 \%$ ) during the summer holydays (when the thermal energy consumption is null) to avoid the over heating of the thermal-liquid Tyfocor, from the turned-off STC.

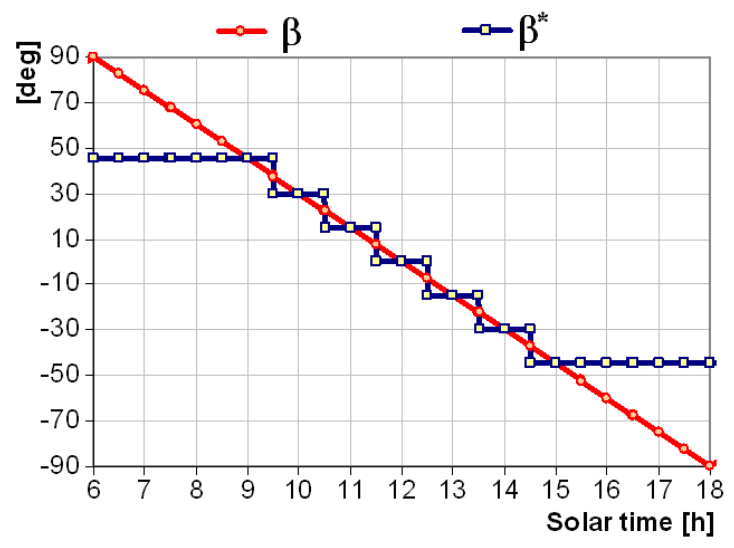

Fig. 2 The continuous variation of the sun diurnal angle $(\beta)$ and the step variation of the STC diurnal angle $\beta^{*}$, depending on the solar time, covering $\Delta \beta^{*}=180^{\circ}$, during the Spring Equinox day.
On the numerical simulations the tracking program for the STC diurnal movement $\left(\beta^{*}\right)$ is modelled as a step curve symmetrically drawn from sun's $\beta$ curve as shown in Fig 2 , while STC' $s$ annual constant elevation is set at the optimum $\gamma^{*}=38^{\circ}[3]$.

\section{Tracking Efficiency and STC efficiency modelling}

The STC efficiency ( $\boldsymbol{\eta}$ sTC) is described as a ratio between the obtained heat quantity delivered by the STC and the solar energy received by the collector and can be calculated with the equation (1) [6], [7].

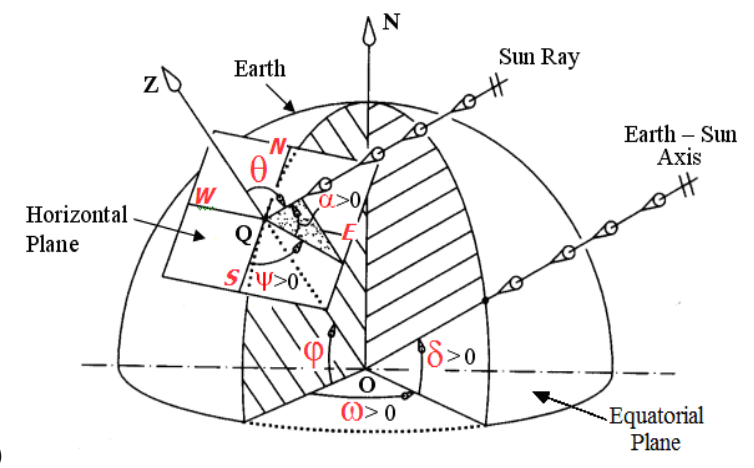

a)

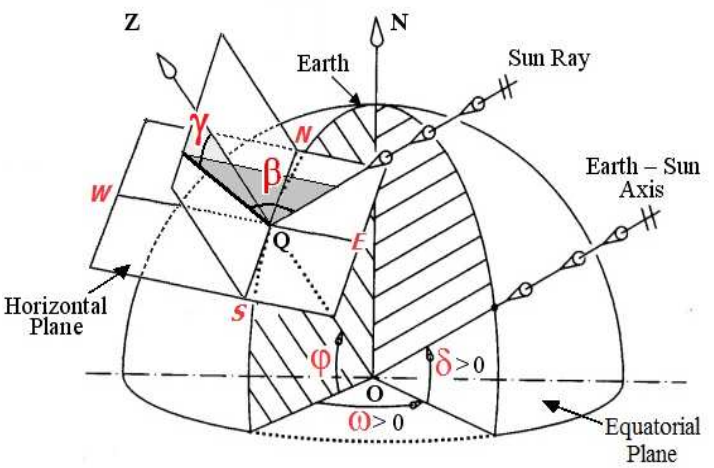

b)

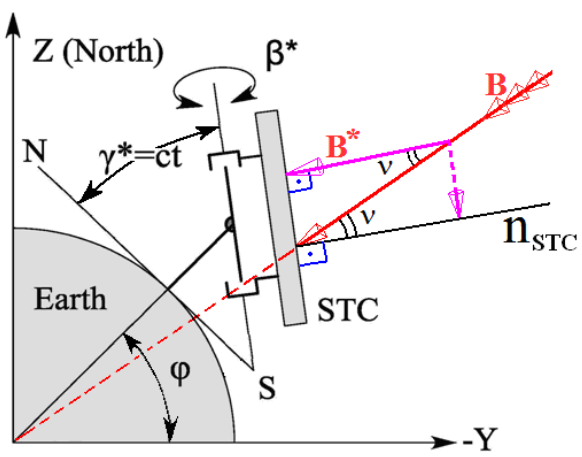

c)

Fig. 3 a) the local azimuth angles $(\alpha, \psi)$ and their afferent global equatorial angles $(\delta, \omega)$; b) the local pseudo-equatorial angles $(\gamma, \beta)$ and their global equatorial angles $(\delta, \omega)$; $)$ a mono-axial tracked STC, of pseudo-equatorial type, with its specific angles $\left(\gamma^{*}\right.$ and $\left.\beta^{*}\right)$ relatively to the Earth, the available beam solar radiation (B), the STC received beam solar radiation $(B *)$, the normal on the STC absorbing surface $\left(\mathbf{n}_{\text {STC }}\right)$ and the incidence angle $(\boldsymbol{V})$ 


$$
\eta_{S T C}=\eta_{0}-k_{1} \cdot \frac{\Delta t}{B *}-k_{2} \cdot \frac{\Delta t^{2}}{B *}
$$

In which:

$\eta_{0}=84 \%$ represents the optical efficiency;

$\mathrm{k}_{1}=3.36 \mathrm{~W} /\left(\mathrm{m}^{2} \mathrm{~K}\right)$ and $\mathrm{k}_{2}=0.013 \mathrm{~W} /\left(\mathrm{m}^{2} \mathrm{~K}^{2}\right)$ are correction factors for the heat loss;

$\Delta \mathrm{t}=30^{\circ}$ represents the temperature average difference of the STC and the ambient air;

$\mathrm{B}^{*}$ - the beam solar radiation received by the mono-axial, tracked STC systems [3], [9].

The tracking efficiency of the STC $\left(\boldsymbol{\eta}_{\text {TRK }}\right)$ is calculated as the ratio between the STC received beam solar energy $\left(\mathrm{E}^{*}\left[\mathrm{Wh} / \mathrm{m}^{2}\right]\right)$ and the available beam solar energy $(\mathrm{E}$ [Wh/m $\left.\mathrm{m}^{2}\right]$ ), according to equation (2) [3], [9]:

$$
\eta_{T R K}=\frac{E^{*}}{E}=\frac{\int B * d t}{\int B d t}
$$

Considering the ideal permanently clear sky conditions $(\mathrm{Fcc}=1)$ [10], the beam solar radiation $(\mathrm{B})$ is calculated according to the German School model equation $(3,4)[3]$, [9], [11]:

$$
B=B_{0} \cdot e^{\left(-\frac{T_{R}}{0.9+9.4 \cdot \sin \alpha}\right)}
$$

in which:

$$
B_{0}=1367 \cdot\left[1+0.334 \cdot \cos \left(0.09856^{\circ} \cdot N-2.72^{\circ}\right)\right]
$$

Where:

$\mathrm{N}$ represents the day number in a year;

$T_{R}$ is the turbidity factor for the considered location [11]

$\alpha$ is the altitude angle of the solar ray Fig. 3a described by the equation [4]:

$$
\alpha=\sin ^{-1}(\sin \delta \sin \varphi+\cos \delta \cos \varphi \cos \omega)
$$

According to the local pseudo-equatorial angles (Fig. 3b), the sun ray unit vector [12] can be described through the elevation angle $(\gamma)$ and the diurnal angle $(\beta)$, given by the following equations Fig. 3b [2], [4], [9]:

$$
\begin{gathered}
\gamma=\sin ^{-1} \frac{\cos \delta \cdot \cos \omega \cdot \sin \varphi-\sin \delta \cdot \cos \delta}{\cos \beta} \\
\beta=\sin ^{-1}(\cos \delta \cdot \sin \omega)
\end{gathered}
$$

in which: $\varphi$ is the location latitude $\left(\varphi=45,65^{\circ}\right.$ lat. $\left.\mathrm{N}\right)$;

$\delta$ represents the sun ray declination Fig. 3a:

$$
\delta=23.45^{\circ} \cdot \sin \cdot \frac{360^{\circ} \cdot(\mathrm{N}-80)}{365},
$$

$\omega$ is the sun ray hour angle Fig. 3a, [4]

$$
\omega=15^{\circ}(t-12),
$$

The STC out-put thermal energy is obtained from the conversion of the normal solar ray component on the STC's absorbing surface. Accordingly, the STC received beam solar radiation is calculated using Lambert's law (10) [3], [9]:

$$
B^{*}=B \cdot \cos v
$$

In which $v$ (Fig. 3c) represents the incidence angle formed between the solar ray unit vector and the normal on the STC absorbing surface:

$$
\begin{gathered}
v=\arccos \left[\cos \beta \cdot \cos \beta * \cdot \cos \left(\gamma-\gamma^{*}\right)+\ldots\right. \\
\left.\ldots+\sin \beta \cdot \sin \beta^{*}\right]
\end{gathered}
$$

To obtain realistic and relevant results for Brasov, Romania in-field conditions, a specific factor was synthesised (Fcc - 'Factor of cloud crossing') to evaluate the beam solar energy loss when crossing the clouds layer [10]. Accordingly, Fcc represents the ratio between the energy of the solar radiation under the clouds layer and the energy of the solar radiation above the clouds layer. Therefore Fcc is applied to the energetic values $\mathrm{E}$ or $\mathrm{E}^{*}$. For Brasov, Romania a monthly variation for Fcc was set (Table 1)

Table 1 Fcc's monthly average values for Brasov, Romania area, [10]:

\begin{tabular}{|c|c|c|c|c|c|c|c|c|c|c|c|c|}
\hline Month & jan & feb & mar & apr & may & jun & jul & aug & sep & oct & nov & dec \\
\hline FCC & 0.28 & 0.30 & 0.33 & 0.38 & 0.44 & 0.52 & 0.51 & 0.51 & 0.44 & 0.38 & 0.30 & 0.28 \\
\hline
\end{tabular}

\section{Numerical simulations}

The optimum annual constant elevation angle $\gamma^{*}$ was identified based on the STC annual energetic response calculus, considering different STC elevation angle values: $\gamma^{*}=\left\{10^{\circ} ; 15^{\circ} ; 30^{\circ} ; 31^{\circ} ; 32^{\circ} ; 33^{\circ} ; 34^{\circ} ; 35^{\circ} ; 36^{\circ}\right.$; $\left.37^{\circ} ; 38^{\circ} ; 39^{\circ} ; 40^{\circ} ; 45^{\circ} ; 50^{\circ} ; 55^{\circ} ; 60^{\circ} ; 65^{\circ} ; 70^{\circ}\right\}$ and an annual hourly step tracking program for $\beta^{*}$. [3]

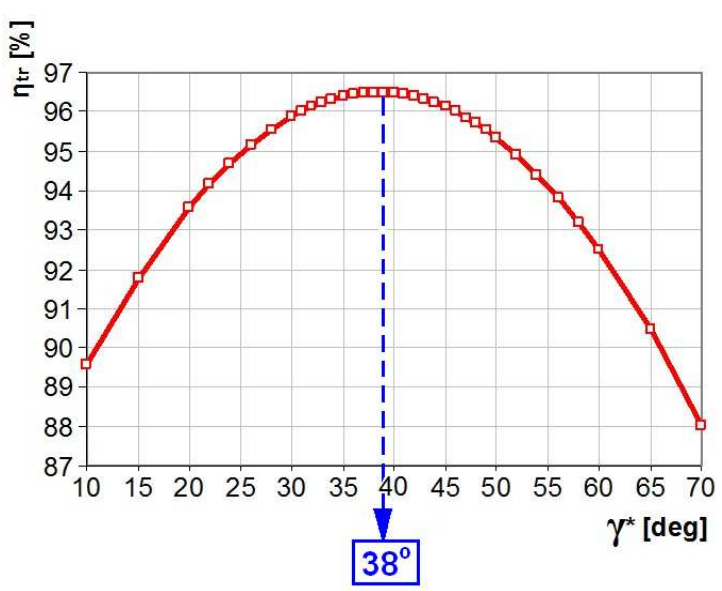

Fig.4 Variation of the STC annual tracking efficiency ( $\left.\eta_{\text {TRK }}\right)$ depending on the elevation $\gamma^{*}\left(\gamma^{*}=10^{\circ} \ldots 70^{\circ}\right)$, for the cloudy sky conditions $(\mathrm{Fcc}<1)$, with determination of the optimum $\gamma^{*}$ $\left(\gamma^{*}=38^{\circ}\right)$ as the angle with the maximum tracking efficiency

To achieve an accurate annual energetic evaluation of the tracked STC for Brasov-Romania implementation site, the year interval was divided into 12 seasons; accordingly, one season is equivalent to one month. To attain the average seasonal (monthly) values for the energetic response calculus, the $15^{\text {th }}$ day of each month is considered as the equivalent seasonal day. 
For each equivalent day of the season were estimated:

- The available beam solar radiation (B) on ideal clear sky conditions $(\mathrm{Fcc}=1)$ and on estimated cloudy sky conditions $(\mathrm{Fcc}<1)$;

- The received beam solar radiation by the tracked STC system $\left(\mathrm{B}^{*}\right)$ on ideal clear sky conditions $(\mathrm{Fcc}=1)$ and on estimated cloudy sky conditions $(\mathrm{Fcc}<1)$;

- The annual tracking efficiency $\left(\eta_{\text {TRK }}\right)$ of the tracked STC;

- The annual STC efficiency $\left(\eta_{\text {STC }}\right)$

To accomplish the restriction of zero energy gain during the summer holidays, the solar rays must never be incident on STC's absorbing surface, so for the thermal liquid (Tyfocor) not to get over-heated on turned-off STC. Therefore, is imposed a one-step $\beta^{*}$ tracking program with an angular stroke $\Delta \beta^{*}$ that is determined further by numerical simulations; so, the absorbing STC surface is facing West - from sunrise to noon and facing East - from noon to sunset.

Therefore, the one-step $\beta^{*}$ tracking programmes, with different seven angular stroke were simulated (as Fig. 5 and 6): $\Delta \beta^{*}=\left\{120^{\circ}\left( \pm 60^{\circ}\right), 130^{\circ}\left( \pm 65^{\circ}\right), 140^{\circ}\left( \pm 70^{\circ}\right), \ldots\right.$, $\left.180\left( \pm 90^{\circ}\right)\right\}$.

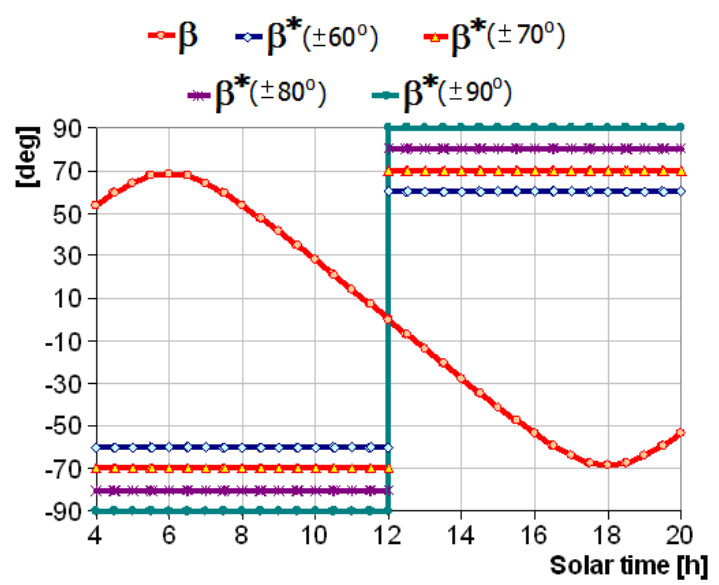

Fig. 5 Variations of the sun diurnal angle $(\beta)$ and four variants for the 1-step STC $\beta^{*}$ tracking program on the summer solstice day: $\Delta \beta^{*}=\left\{120^{\circ}\left( \pm 60^{\circ}\right) ; 140^{\circ}\left( \pm 70^{\circ}\right) ; 160^{\circ}\left( \pm 80^{\circ}\right) ; 180^{\circ}\left( \pm 90^{\circ}\right)\right\}$

Though, in these first six cases the tracked STC fails to accomplish the zero energy gain imposed for summer holiday interval because the solar rays come to be incident on the absorbing STC surface during the noon interval (Fig. 6):

- From 10.0 to 14.0 when $\Delta \beta^{*}=120^{\circ}\left(= \pm 60^{\circ}\right)$

- From 10.3 to 13.7 when $\Delta \beta^{*}=130^{\circ}\left(= \pm 65^{\circ}\right)$

- From 10.7 to 13.3 when $\Delta \beta^{*}=140^{\circ}\left(= \pm 70^{\circ}\right)$

- From 11.0 to 13.0 when $\Delta \beta^{*}=150^{\circ}\left(= \pm 75^{\circ}\right)$

- From 11.4 to 12.6 when $\Delta \beta^{*}=160^{\circ}\left(= \pm 80^{\circ}\right)$

- From 11.7 to 12.3 when $\Delta \beta^{*}=170^{\circ}\left(= \pm 85^{\circ}\right)$

When the beam solar radiation is incident on STC's surface (Fig. 3c) it's normal component is converted into thermal energy and thus the thermal liquid (Tyfocor) is warming-up. Tyfocor's temperature, on a stationary regime, should not get over the value of $170^{\circ}$. This stationary warming-up effect on the thermal liquid will be analysed and evaluated on a future study. Herein is evaluated only the STC received beam solar radiation and the correspondent STC received solar energy.

For the daily intervals on the summer holidays it can be observed that while diminishing $\Delta \beta^{*}$ the received beam solar radiation $\mathrm{B}^{*}$ increases (Fig. 7) and consequently the correspondent solar energy $\mathrm{E}\left(\mathrm{B}^{*}\right)$ increases (Fig. 8), which, by solar conversion, warms-up the Tyfocor and endangers the safety of the turned-off STC during the summer holidays interval. Accordingly, the correspondent increase of the $\eta_{\text {STC }}$ (Fig. 9), does not represent a positive effect in this particular situation.

Therefore, to avoid any inconveniences, to ensure the safe working conditions and to obtain a null solar energy gain on the summer holidays interval $\mathrm{E}\left(\mathrm{B}^{*}\right)=\mathrm{Wh} / \mathrm{m}^{2}, \Delta \beta^{*}$ is set at the value of $180^{\circ}\left(= \pm 90^{\circ}\right)$.

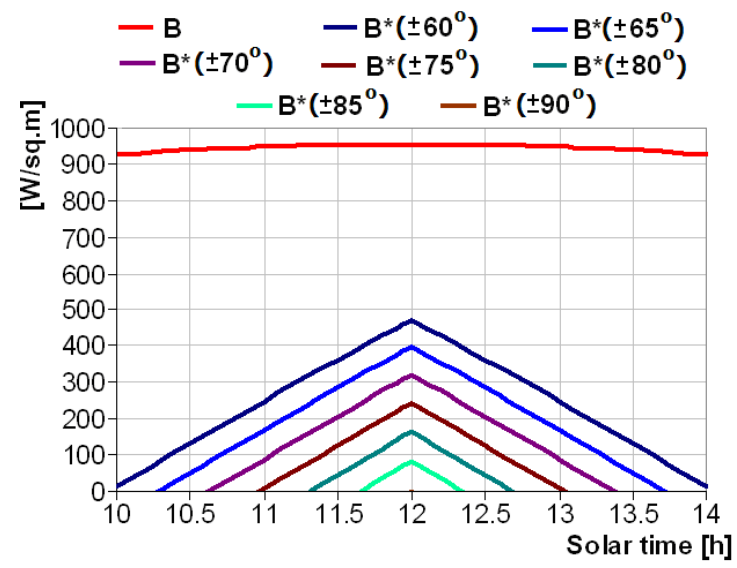

Fig. 6 The beam solar radiation (B) and the STC received beam solar radiation $\left(\mathrm{B}^{*}\right)$, around the noon, for the summer holidays interval, considering the optimum $\gamma^{*}=38^{\circ}[3]$ and the STC 1step $\beta^{*}$ tracking programmes with different angular stroke $\Delta \beta^{*}=$ $\left\{120^{\circ}, 130^{\circ}, 140^{\circ}, 150^{\circ}, 160^{\circ}, 170^{\circ}, 180^{\circ}\right\}$ (Fig. 5)

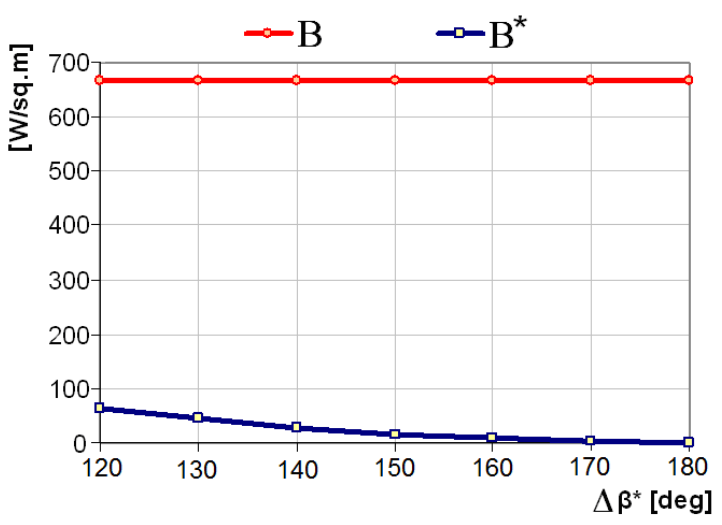

Fig. 7 The average beam solar radiation (B) and the average STC received beam solar radiation $\left(\mathrm{B}^{*}\right)$, depending on the angular stroke $\Delta \beta^{*}$, for the summer holidays interval, considering $\gamma^{*}=38^{\circ}$ and STC 1 -step $\beta^{*}$ tracking program

For September to June interval, a large $\Delta \beta^{*}$ is theoretically needed to capture the most of the beam solar radiation, though, practically a reduced $\Delta \beta^{*}$ must be imposed to protect the STC pipe structure during the 
tracking moves. Therefore different diurnal angular strokes are imposed on $\Delta \beta^{*}=\left\{0^{\circ} ; 30^{\circ}\left( \pm 15^{\circ}\right) ; 60^{\circ}\left( \pm 30^{\circ}\right)\right.$; $\left.90^{\circ}\left( \pm 45^{\circ}\right) ; 120^{\circ}\left( \pm 60^{\circ}\right) ; 150^{\circ}\left( \pm 75^{\circ}\right) ; 180^{\circ}\left( \pm 90^{\circ}\right)\right\}$.

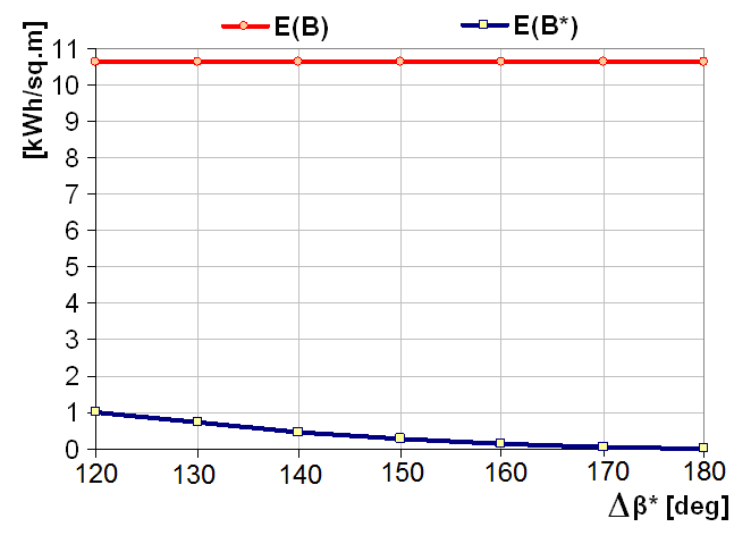

Fig. 8 The daily variations of the available beam solar radiation energy E (B) and of the STC received energy E (B*), on summer holidays interval, for the optimum $\gamma^{*}=38^{\circ}$ and STC 1 -step $\beta^{*}$ tracking programs depending on angular stroke $\Delta \beta^{*}$

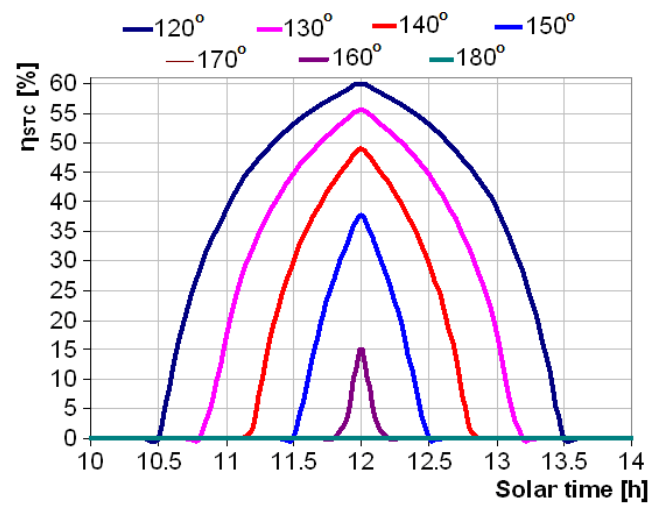

Fig. 9 The daily STC efficiency ( $\eta_{\text {sTC }}$ ) depending on the solar time, for the summer holidays interval, considering the optimum $\gamma^{*}=38^{\circ}$ and different angular stroke values: $\Delta \beta^{*}=\left\{120^{\circ}, 130^{\circ}\right.$, $\left.140^{\circ}, 150^{\circ}, 160^{\circ}, 170^{\circ}, 180^{\circ}\right\}$

The tracking efficiency is calculated for different seven values of the angular stroke: $\Delta \beta^{*}=\left\{0^{\circ} ; 30^{\circ}\left( \pm 15^{\circ}\right)\right.$; $60^{\circ}\left( \pm 30^{\circ}\right) ; \quad 90^{\circ}\left( \pm 45^{\circ}\right) ; \quad 120^{\circ}\left( \pm 60^{\circ}\right) ; \quad 150^{\circ}\left( \pm 75^{\circ}\right) ;$ $\left.180^{\circ}\left( \pm 90^{\circ}\right)\right\}$, considering both ideal clear sky conditions $(\mathrm{Fcc}=1)$ and cloudy sky conditions $(\mathrm{Fcc}<1)[10]$.

The results are compared to identify high tracking efficiency and high STC efficiency values corresponding to minimum diurnal angular stroke $\left(\Delta \beta^{*}\right)$.

According to Fig $10 \Delta \beta^{*}=90^{\circ}\left(= \pm 45^{\circ}\right)$ is the minimum angular stroke needed to reach an over $90 \%$ tracking efficiency $(92 \%)$. Accordingly, it is not profitable to enlarge STC's diurnal angular stroke from $\Delta \beta^{*}=90^{\circ}$ to $\Delta \beta^{*}=120^{\circ}$ to gain a plus of $2 \%$ tracking efficiency, equivalent to $21 \mathrm{KWh} / \mathrm{sq} . \mathrm{m} /$ year. Moreover a $\Delta \beta^{*}=90^{\circ}$ can rely on the simplest, least expensive actuating variant: an ordinary linear actuator.

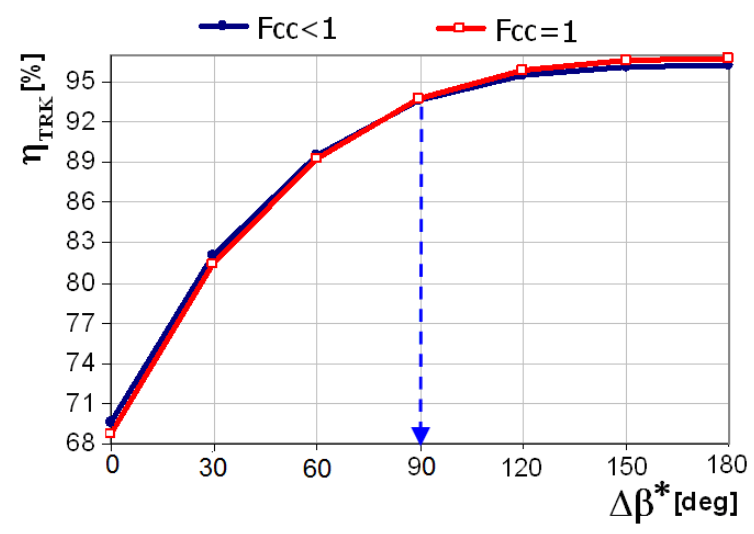

Fig. 10 The seasonal STC tracking efficiency ( $\left.\eta_{\text {TRK}}\right)$, depending on the angular stroke $\Delta \beta^{*}$, for the September-June season, the elevation $\gamma^{*}=38^{\circ}$ on the pre-requisites: clear sky conditions $(\mathrm{Fcc}=1)$ and cloudy sky $(\mathrm{Fcc}<1)$.

After setting the optimum $\Delta \beta^{*}=90^{\circ}\left( \pm 45^{\circ}\right)$ for the September-June interval and $\Delta \beta^{*}=180^{\circ}\left( \pm 90^{\circ}\right)$ for the summer holidays interval, further numerical simulations are done to evaluate the annual STC efficiency on both ideal clear sky conditions $(\mathrm{Fcc}=1)$ and cloudy sky conditions $(\mathrm{Fcc}<1)[10]$.

In Fig. 11 is attained the comparison between the STC efficiency levels and the corresponding tracking efficiency values. Herein can be observed that during the summer holidays interval $\eta_{\text {STC }}, \eta_{\text {TRK and }} \eta_{\text {TOT }}=\eta_{\text {STC }}$ 证 are null, accomplishing the zero energy response requirement. Thus the mono-axial, tracked STC is well preserved while is turned-off during the highest temperature in-field conditions. Accordingly, the available beam solar radiation energy multiplied with $\eta_{\text {TOT }}\left(=\eta_{\text {STC }} \eta_{\text {TRK }}\right)$ gives the value of the thermal energy delivered form STC by solar conversion.

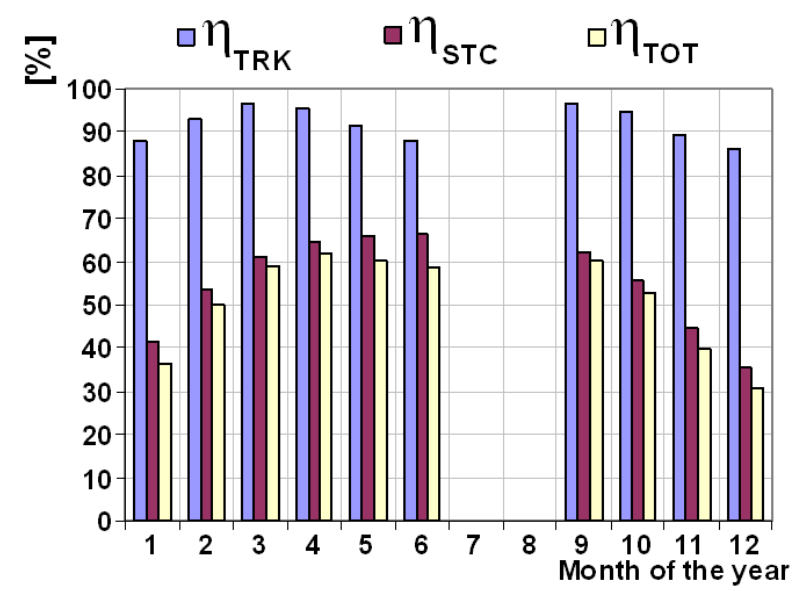

Fig.11 The monthly STC efficiency ( $\left.\eta_{\text {sTC }}\right)$, tracking efficiency $\left(\eta_{\text {TRK }}\right)$ and total efficiency $\left(\eta_{\text {TOT }}=\eta_{\text {sTC }} \cdot \eta_{\text {TRK }}\right)$, for the constant elevation $\gamma^{*}=38^{\circ}$ and angular diurnal stroke: $\Delta \beta^{*}=90^{\circ}\left( \pm 45^{\circ}\right)$ for September-June season and $\Delta \beta^{*}=180^{\circ}\left( \pm 90^{\circ}\right)$ for the summer holidays interval 


\section{Conclusions}

The numerical simulations lead to the following results:

The optimum tracking law for the mono-axial, tracked STC, designed to be implemented on Transilvania University Campus, Brasov-Romania (45,65lat N.) consists of:

$>$ An annual constant elevation $\gamma^{*}=38^{\circ}$;

$>$ An hourly step tracking program for the diurnal movement, for September-June season, with an optimum angular stroke: $\Delta \beta^{*}=90^{\circ}\left( \pm 45^{\circ}\right)$;

$>\mathrm{A}$ one step tracking program for the diurnal movement, for the summer holidays interval, with an optimum angular stroke: $\Delta \beta^{*}=180^{\circ}\left( \pm 90^{\circ}\right)$.

Based on the above results are obtained the following efficiencies: the seasonal tracking efficiency for September-June season is: $\eta_{\text {TRK }}=92,33 \%$ on cloudy sky conditions and $92,36 \%$ on clear sky conditions, while for the summer holidays interval: $\eta_{\text {TRK }}=0 \%$. Moreover, these results show that on September-June interval the monoaxial STC receives with $\Delta \eta_{\text {TRK }}=21 \%$ more beam solar radiation than an optimum fix tilt $\operatorname{STC}\left(\gamma^{*}=36^{\circ}, \beta^{*}=0^{\circ}\right)$.

Another main conclusions shows that both the maximum monthly tracking efficiencies and the maximum monthly total efficiencies are registered for March, April, May, September and October.

During the summer holiday interval the mono-axial, tracked STC reaches the required $\eta_{\mathrm{STC}}=0 \%$, while the fix tilt STC is reaching an inadequate $\eta_{\mathrm{STC}}=58 \%$ meaning either an important waste of energy when the STC is turned-on, either the explosion of the thermal liquid on the turned-off STC.

Considering all these, the proposed mono-axial tracked STC represents an optimised tracking solution for a future implementation in Transilvania Brasov University campus, designed to successfully attain the specific requirements: a zero energetic response during the zero consumption intervals and an over $90 \%$ gain from the available beam solar radiation during the rest of the year.

\section{Acknowledgements}

This paper is supported by the Sectoral Operational Programme Human Resources Development (SOP HRD), financed from the European Social Fund and by the Romanian Government under the contract number POSDRU/6/1.5/S/6

\section{References}

[1] http://www.unitbv.ro/Genius_campus/

[2] B.G. Burduhos, "Optimizarea mecanismelor de orientare de tip pseudo-ecuatorial utilizate pentru creşterea eficienţei conversiei panourilor fotovoltaice individuale", phd thesis, Brasov, Romania (2009), pp. 125

[3] V.-E. Dombi, M.D. Moldovan and B.G. Burduhos, "Step orientation system for a solar thermal platform", KOD 2010 - The 6th International Symposium about forming and design in mechanical engineering "Shape, Mechanical and Industrial Design of Products in Mechanical Engineering 2010", Palic, Serbia (2010).

[4] I. Vişa, D. Diaconescu, V. Dinicu and B. Burduhos, "On the Sun-Earth Angles Used in the Solar Trackers' Design. Part 1: Modelling", in Annals of the Oradea University, Fascicle of Management and Technological Engineering, CD-ROM Edition, Vol. VI (XVI), Oradea, Romania (2007).

[5] I.N. Tatu and C. Alexandru, "Tracking mechanism for a group of photovoltaic modules", in 25th European Photovoltaic Solar Energy Conference and Exhibition / 5th World Conference on Photovoltaic Energy Conversion, Valencia, Spain (2010).

[6] http://www.viessmann.com/com/en

[7] EN 12975-2/2001 "Thermal solar systems and components. Solar collectors. Test methods", pp. 91.

[8] I. Vişa, D.V. Diaconescu, V. Popa and B.G. Burduhos, "Quantitative Estimation of the Solar Radiation Loss in the Braşov Area", The International Conference on Materials Science and Engineering BRAMAT 2009, Environmental Engineering and Management Journal, Braşov, Romania (2009), pp. 843-848.

[9] D. Diaconescu, I. Vişa, B. Burduhos and R. Saulescu, "On the Dependence between the Step Orientation and the Received Beam Solar Radiation of a PV Panel". Part II: “The Step Pseudo-Equatorial Orientation”, ICREPQ'08 International Conference on Renewable Energies and Power Quality, Santander, Spain (2008).

[10] D. Diaconescu, I. Vişa, I. Hermenean and M. Vatasescu, "Clouds Influence o the solar Radiation for a Mountain Location"; In: Environmental Engineering and Management Journal, Vol.8, No.4 (2009), pp. 849-853.

[11] M.M. Vatasescu, D. Diaconescu, A. Duţă and B.G. Burduhos:"Atmospheric pollution evaluation in Brasov Romania based on turbidity factor analisys", IC-ANMBES - Analytical and Nanoanalytical Methods for Biomedical and Environmental Sciences, Braşov, Romania (2010).

[12] I. Vişa, D. Diaconescu, V. Dinicu and B. Burduhos, "The Incidence Angles of the Trackers Used for the PV Panels' Orientation". Part II: Azimuthal Trackers, ICEEMS International Conference on Economic Engineering and Manufacturing Systems, published in Jurnalul RECENT, Vol. 8, nr. 3a(21a), Braşov, Romania (2007). 